\section{The impact of linguistic style on customer satisfaction: a cross- cultural empirical study in Ecuador}

Linguistic style and customer satisfaction

\author{
Alei Fan
}

School of Hospitality and Tourism Management, Purdue University, West Lafayette, Indiana, USA

Hubert B. Van Hoof

School of Hospitality Management, The Pennsylvania State University, University Park, Pennsylvania, USA

Xueting Dou

School of Hospitality and Tourism Management, Purdue University, West Lafayette, Indiana, USA, and

Ana Lucia Serrano

College of Hospitality Sciences, University of Cuenca, Cuenca, Ecuador

\begin{abstract}
Purpose - Drawing on the dual process theory and the cultural dimension of power distance, the current research investigates the impact of a specific service clue - the linguistic style of address forms (salutation) in hotel manager letters to guests - on customer satisfaction in a hotel context in Ecuador.

Design/methodology/approach - Following an experimental design research approach, this research conducted a series of two studies to examine how customers' cultural values (high vs low power distance), linguistic style of address forms (formal vs casual) and service valence (service success vs service failure) together influenced customer satisfaction. Specifically, Study 1 examined the service success condition, and Study 2 investigated the service failure condition.

Findings - The research results show that, in the service success condition, customers follow their distinct cultural orientations (high vs low power distance) when responding to the different linguistic styles (formal vs casual). On the other hand, in the service failure situation, as customers desire for expressions of respect that can be reflected in a formal address form, the level of satisfaction is lower when the casual address form is used in guest communications, regardless of customers' cultural orientations in power distance.

Originality/value - This research adds to existing cross-cultural service research, particularly in terms of service valence, and provides practical implications for enhancing service providers' cultural awareness and sociolinguistic competence to effectively communicate with customers from diverse cultural backgrounds.
\end{abstract}

Keywords Cross-cultural study, Power distance, Linguistic service clue, Information processing theory, Customer satisfaction, Service valence

Paper type Research paper

\section{Introduction}

In international travel, cross-cultural interaction between customers and service providers is inevitable (Koc, 2019; Lam et al., 2020), and misunderstanding between the two parties due to different cultural and language backgrounds happens. Individuals are influenced by their

(C) Alei Fan, Hubert B. Van Hoof, Xueting Dou and Ana Lucia Serrano. Published in International Hospitality Review. Published by Emerald Publishing Limited. This article is published under the Creative Commons Attribution (CC BY 4.0) licence. Anyone may reproduce, distribute, translate and create derivative works of this article (for both commercial and non-commercial purposes), subject to full attribution to the original publication and authors. The full terms of this licence may be seen at http:// creativecommons.org/licences/by/4.0/legalcode
Received 6 April 2021 Revised 29 May 2021 Accepted 12 July 2021 
own cultural norms and values when interpreting and evaluating service experiences (Mattila, 2019; Patterson et al., 2006), and any misinterpretations may induce misunderstanding and result in customer dissatisfaction. Thus, cross-cultural studies are needed to understand the cultural drivers and their impacts on intercultural service encounters and global business practices (Mattila, 2019; Ruiz-Equihua et al., 2020). Enhanced cross-cultural awareness is important in efforts to attract international tourists and to develop the inbound tourism market, particularly to struggling economies like Ecuador that greatly depends on inbound tourism income.

Hofstede (1984) defines culture as "the collective programming of the mind which distinguishes the members of one human group from another" (p. 21). Hofstede's cultural dimension scores have been the most frequently used benchmarks in investigating crosscultural issues in tourism and hospitality (Chen et al., 2019; Chon et al., 2020; Li, 2014). In these studies, country is often used as a proxy for culture, as national culture profoundly influences the way in which individuals establish and maintain relationships and express their perceptions and emotions (Mattila, 2019; Surachartkumtonkun et al., 2013). One of the dominant cultural dimensions examined in the extant literature is power distance, the extent to which less powerful group members accept that power is distributed unequally (de Mooij, 1998; Mattila, 2019). A customer's power-distance orientation has a strong impact on his/her perceptions of service quality, sensitivity to violations of fundamental needs, and attitudes and behaviors toward what are perceived as "unequal" counterparts in service encounters (Donthu and Yoo, 1998; Lee, 2015; Surachartkumtonkun et al., 2013).

In the extant cross-cultural research, cultural comparisons are predominantly made between the United States or Western Europe on the one side and Asian countries on the other. Research conducted on this topic in a South American context is scarce (Fan et al., 2016; Ruiz-Equihua et al., 2020). To fill this gap, this research examines the effects of culture-bound customer responses to hotel manager communications with guests in a hotel setting in Ecuador, a South American country that has extraordinary tourism resources and that is trying to develop conventional tourism as an important economic activity (Ruiz-Ballesteros, 2011). According to Hofstede's cultural score, Ecuador, with a score of 78, ranks as a high power-distance society, a society that generally believes that inequalities among people are simply a fact of life (Hofstede Insights, n.d.). Conversely, Western cultures, such as the United States (with a score of 40), have much lower power-distance ratings.

The acceptance of power inequalities shapes how people of varying levels of power interact (Javidan and House, 2001). In general, people from high power-distance cultures are inclined to reinforce ingroup-outgroup differences and are likely to retain the social distance inherent in hierarchical relationships (Mattila, 2000). Customers from high powerdistance cultural backgrounds are more sensitive to formality-related factors of service quality (e.g. inappropriate language use) than their low power-distance counterparts (Daniels and Greguras, 2014; Surachartkumtonkun et al., 2013). For example, prior research indicates that high power-distance Japanese customers consider the friendly service style of hospitality in Western cultures, where frontline employees casually greet and chat with guests, to be disrespectful (Winsted, 1997). The current research aims to further investigate those differences through the lens of a customer service clue- the linguistic style used in addressing guests (i.e. formal vs casual) - in a hotel context and to test whether the two contrasting linguistic styles may influence the service evaluation by customers from different cultures (i.e. high power-distance Ecuadorians vs low powerdistance Westerners) across two different service situations (i.e. service success vs service failure).

The increasingly multicultural global travel and tourism marketplace makes it necessary for hospitality and tourism practitioners to possess cultural awareness and sociolinguistic 
competence in order to effectively communicate with customers from diverse backgrounds (Blue and Harun, 2003; Lam et al., 2020; Manoharan et al., 2021). The present study provides new insights into cross-cultural service encounters by focusing on the relatively overlooked service clue of address forms in hotel guest letters in an understudied region of South America. Drawing on the dual information process theory, this research further investigates how customers' cultural orientation might become a salient factor related to the service valence (i.e. service success vs service failure), which has rarely been taken into account in previous research. Industry practitioners could leverage the findings from this research to better manage intercultural host-guest interactions in different service situations. To achieve these research goals, we first review the relevant literature to develop the hypotheses, which guides the subsequent empirical examinations.

\section{Theoretical background and hypotheses}

In this section, we discuss the overarching framework of dual process theory and explain how linguistic styles as a service clue may impact customers' information processing before we examine the cultural dimension of power distance and its effects on service. Based on the theoretical framework, research hypotheses are proposed accordingly.

\section{Customer information processing and linguistic service clues}

Cognitive psychology research finds that people process information through a dual system of reasoning: one is automatic, fast and intuitive and is referred to as System 1 thinking. The other is controlled, slow and conscious and is called System 2 thinking (Kahneman, 2011; Samson and Voyer, 2012). This System 1 and System 2 framework has been used to understand the duality of the human mind and the role of automatic and deliberative processes in consumer persuasion and attitude change, in judgment and decision-making and in consumption behaviors (Samson and Voyer, 2012). The current research draws on this overarching dual process framework to investigate how customers may respond differently to various linguistic service clues (e.g. casual vs formal communication style) due to different information processing routes (i.e. System 1 vs System 2 thinking).

Customers rely on numerous clues embedded in service performances and interactions to appraise a complex service experience (Mattila, 1999). In the labor-intensive, interactive services performed in hospitality, particularly salient types of clues emerge from the service providers' behavior and appearance, such as their choice of words, tone of voice, body language, level of enthusiasm or the neatness and appropriateness of their dress (Berry et al., 2006; Kim and Baker, 2019). Termed as "humanic clues," these largely intangible service elements greatly impact how customers feel about themselves during a service transaction, and enhanced attention to these clues is therefore vitally important when service providers attempt to exceed customers' expectations and enhance their satisfaction and loyalty (Berry et al., 2006).

Linguistic expressions associated with host-guest interactions are also a humanic service clue. Previous research has investigated the role of linguistic or communication styles in various settings and from different angles (Wang et al., 2019). For example, in the context of consumer-brand interactions on social media, a brand's tone of voice has an effect on consumers' brand trust and purchase intentions (Barcelos et al., 2018; Gretry et al., 2017). Moreover, researchers find that restaurant project pitches using certain linguistic styles (i.e. more concrete, less interactive and low in psychological distancing) are more effective in raising money through crowdfunding (Koh et al., 2020). Nonetheless, linguistic service clues in the service consumption process are likely to be taken for granted as an implicit feature of hospitality practices and have received limited scholarly attention (Blue and Harun, 2003).
Linguistic style and customer satisfaction

$\longrightarrow$


The current study focuses on such a specific clue - the use of the address form in hotel guest letters (e.g. "Dear Sir/Madam" vs "Dear John/Mary") — and examines how customer satisfaction may be impacted by it.

In general, linguistic clues used in hospitality services should reflect employee courtesy, emphasizing respect for and consideration of customers (Gotlieb et al., 2004). Under normal circumstances, the standardized polite language or linguistic style used in service interactions is processed automatically (Pogacar et al., 2018). The message recipients (i.e. customers) may be aware of how politely the information is communicated, but they tend to process the message with little cognitive effort or attention, following System 1 thinking (Kahneman, 2011; Pogacar et al., 2018). Yet, when disfluency between the perceived and expected information appears, people are likely to adopt System 2 thinking-a more elaborative processing mode, devoting more cognitive capacity to the information incongruence and generating less favorable attitudes toward the message sender (Moors, 2016; Pogacar et al., 2018). The effect of linguistic service clues on customer satisfaction therefore essentially depends on how customers process and interpret the information conveyed by the clues, that is, whether the expected level of respect reflected as employee courtesy is perceived in the message.

Address forms are an integral part of polite language use and have special pragmatic functions. Various address forms set the tone for the communication that follows and indicate the relative power and status of the interacting parties (Wood and Kroger, 1991). In a hotel setting, "Sir"/"Madam" or "Mr."/"Ms." followed by the surname are often used to address guests, showing formal respect and refined politeness conventions (Blue and Harun, 2003; Sirikhan and Prapphal, 2011). However, the proper usage of address forms in one situation may not be readily transferable to another, as it depends very much on the way the interacting participants perceive their roles and relations between each other (Blue and Harun, 2003; Solomon et al., 1985). In other words, notions of propriety and politeness of address forms are, to a large extent, context-specific and culture-bound (Blue and Harun, 2003).

\section{Power distance and customer service evaluation}

Culture often resides in values and collective beliefs (Hofstede, 2001). Cultural values signal what is desirable and undesirable and specify individuals' typical or general preferences in a given situation (Daniels and Greguras, 2014; Glikson et al., 2019). Power distance is such a cultural value that captures the different solutions to the basic problem of human inequality (Hofstede, 2001). Power symbolizes a higher status, more privilege and more wealth (Patterson et al., 2006). In high power-distance cultures, people with power are seen as respected, superior and inaccessible, while those with less power are generally submissive, loyal and deferential (Daniels and Greguras, 2014; Glikson et al., 2019).

Societies scoring low on power distance tend to minimize the differences between those with and without power: they tend to be more egalitarian, favor the decentralization of activities and expect stronger participation in decision-making (Javidan and House, 2001; Patterson et al., 2006). According to the Power Distance Index scores listed for 76 countries worldwide, Eastern European, Latin American, Asian and African countries score high on the power dimension, while Germanic and English-speaking Western countries have much lower power distance scores (Hofstede, 2011).

In the context of hospitality services, a myriad of studies have investigated the significant influence of customers' cultural backgrounds on their service expectations, perceptions of service quality, emphasis on specific service attributes and overall satisfaction (Schuckert et al., 2015). The dimension of power distance in particular has proven useful in analyzing culturally related service consumption and experience 
(Mattila, 1999, 2000; Su et al., 2018). Research has found that high power-distance customers attach more importance to tangible service attributes but have lower expectations regarding the reliability of service quality and a higher tolerance toward service failure (Dash et al., 2009; Donthu and Yoo, 1998; Surachartkumtonkun et al., 2013). Furthermore, previous studies have also established that in cultures of high powerdistance, customers often feel superior to service providers in the social hierarchy, and therefore expect a high level of personalized or customized service and a strong display of courtesy and attentiveness from service providers (Kim and Aggarwal, 2016; Lam et al., 2020; Mattila, 1999).

In highly interactive service settings such as hotels, the interactions between customers and service personnel constitute a major determinant of customer satisfaction (Patterson et al., 2006). Adapting the social psychological perspective to human interactions, Solomon et al. (1985) conceptualize these service encounters as a form of role performance, in which each participant should enact learned, appropriate behavior patterns along two dimensions - the content and the style of communication - in order for the transaction to proceed smoothly. The style of communication in particular recognizes the centrality of ritualistic or ceremonial elements in service encounters (Solomon et al., 1985).

Customers' expectations and preferences for styles of service encounters are inevitably shaped by their cultural values. For example, previous research indicates that high powerdistance cultural groups, such as Asian customers, expect the status differences between themselves and service employees to be reflected in the service provision; they seek more formality in service styles and are more interested in the ritualistic aspects of employee behavior (Ladhari et al., 2011; Mattila, 2000; Winsted, 1997). Conversely, low power-distance Western customers generally do not consider formality-related behaviors (e.g. dress nicely, proper language) as significant factors related to their service satisfaction (Winsted, 1997). Instead, the efficiency and promptness of service delivery is highly valued by customers from those cultures (Mattila, 2000; Winsted, 1997).

Since the degree of congruence between customers' expected and perceived styles of service encounters substantially affects the overall customer satisfaction (Mattila, 1999; Solomon et al., 1985), service providers will benefit from gaining sophisticated insights into how customers' preferences of service styles differ across various cultural groups and service scenarios. Yet, little research has been done to empirically investigate the impact of different communication styles in service encounters on customer satisfaction and to further clarify the boundary conditions or the underlying psychological mechanisms. The current study aims to fill these research gaps in the hospitality literature.

\section{Hypothesis development}

In a low power-distance culture, it is appropriate for people with different levels of seniority or status to address each other casually by using first names (Zielinska, 2020), and in hotel service encounters, such informality might indicate a warm welcome and make customers feel "just like home" (Berry et al., 2006; Blue and Harun, 2003). However, in a high powerdistance culture, individuals with less power are expected to address their superiors formally to show their acknowledgment of differences in status (Wood and Kroger, 1991). For example, a study of prospective hotel employees in Thailand finds that potential employees of higher-level professional competence would demonstrate power/hierarchy consciousness by using formal address forms in interacting with customers (Sirikhan and Prapphal, 2011).

In addition to cultural values, the service valence (i.e. service success vs failure) may make certain linguistic styles more salient than others. As customers generally expect

\section{Linguistic style and customer satisfaction}


service companies to know their business and to keep their core service promises, a successful service delivery puts customers in a mental position characterized by mindlessness (Berry et al., 2006; Solomon et al., 1985) or the automatic and intuitive System 1 information processing mode (Kahneman, 2011), despite the fact that their overall attitudes and behaviors will still be subject to the impact of their internal characteristics, such as cultural orientation. Therefore, we propose that after a service success, as their inherent cultural values take effect through System 1 thinking, Ecuadorian customers (i.e. high power-distance) will perceive a higher degree of information congruence when they read a hotel guest letter in which they are addressed in a formal way (i.e. by title and last name) rather than in a casual way (i.e. by first name). They will show higher-level service evaluation (i.e. greater satisfaction) when addressed formally rather than casually.

Western customers (i.e. low power-distance) on the other hand will perceive the same levels of congruence regardless of service communication styles because they do not consider the formal address form by service providers as more appropriate or the casual one as impolite or offensive. They will not show any difference in satisfaction levels based on the address forms in the guest letter. Accordingly, the following hypotheses are posited:

H1a. After a service success, Ecuadorian customers show a higher level of satisfaction when they are addressed formally rather than casually in a hotel guest letter.

H1b. After a service success, Western customers show a similar level of satisfaction regardless of whether they are addressed formally or casually in a hotel guest letter.

When confronted with a service failure in which the service performance deviates from the scripted path, customers have to expend more cognitive effort to orient their behaviors to the unpredicted situation (Solomon et al., 1985). Previous research indicates that mood or affective states play a role in the adopted information processing strategy: people in a negative mood are more likely to use System 2 thinking and will overly elaborate on the received messages (Samson and Voyer, 2012; Schwarz, 2000). Therefore, when faced with a service failure, customers may switch from a default cultural mindset (System 1 thinking) to a more deliberate and analytical information processing mindset (System 2 thinking). Moreover, as their basic needs are not met during a service failure, customers tend to interpret it as receiving inadequate respect or consideration from the service providers and thus perceive damaged self-esteem or decreased sense of self-worth (Du et al., 2010; Surachartkumtonkun et al., 2013). As a result, customers may focus on service clues such as whether they are addressed in a professional or polite way in order to evaluate their experiences in a service failure context. In this situation, a more explicit display of employee courtesy or formal communication style would be heavily weighted when customers appraise their service experiences. Such ritualistic elements are necessary to compensate customers for their unfulfilled desires to receive proper respect and consideration from the service staff (Du et al., 2010; Gotlieb et al., 2004; Patterson et al., 2006). In other words, a feeling of respect extrapolated from service communication styles may explain the customers' postfailure satisfaction levels.

Hence, we propose that after a service failure and the consequent deliberate information processing, the service evaluation by both Ecuadorian and Western customers will be lower when they read a guest letter in which they are addressed casually rather than formally. This effect of address forms on customer satisfaction in the service failure scenario is due to the customers' feeling of being respected triggered by different communication styles. The proposed hypotheses are as follows: 
H2. After a service failure, both Ecuadorian and Western customers show a lower level of satisfaction when they are addressed casually rather than formally in a hotel guest letter.

H3. The impact of linguistic styles of address forms (formal vs casual) on customers' postfailure satisfaction is mediated by customers' feeling of being respected.

The conceptual model of this research is displayed in Figure 1.

\section{Methodology and results}

In a series of two studies, we examined how customers' cultural values (high vs low power distance), linguistic style of address forms (formal vs casual) and service valence (service success vs service failure) together influence customer satisfaction. Study 1 examined the service success condition, and Study 2 investigated the service failure situation.

Following previous cross-cultural research, we used countries as proxies for different cultural backgrounds, and the cultural value was operationalized at the individual level for confirmation (Daniels and Greguras, 2014). Specifically, we recruited local Ecuadorians as participants from a high power-distance background and Western tourists and expatriates from countries such as the United States as their low power-distance counterparts. Participants of this research were recruited in the city of Cuenca, which is one of the most popular destinations in Ecuador for tourists and expats from the United States and other Western countries. Research assistants from a major local university went to local tourism attractions, restaurants, social gatherings and expat events, asking both locals and Westerners to participate in the study. Once they had agreed, the participants first read hypothetical service scenarios and guest letters and then answered survey questions based on the materials they had read.

\section{Study 1 - service success}

Design and stimuli. Study 1 employed a 2 (culture background: high vs low power distance) by 2 (linguistic style: formal vs casual) between-subjects quasi-experimental design. Participants from each cultural background were randomly assigned to one of the two experimental scenarios. First, all participants read a hypothetical service success scenario: "For a recent trip, you had booked two connecting rooms for yourself and your friend. Upon checking-in, the hotel was fully booked but the front desk clerk took great effort to find two rooms

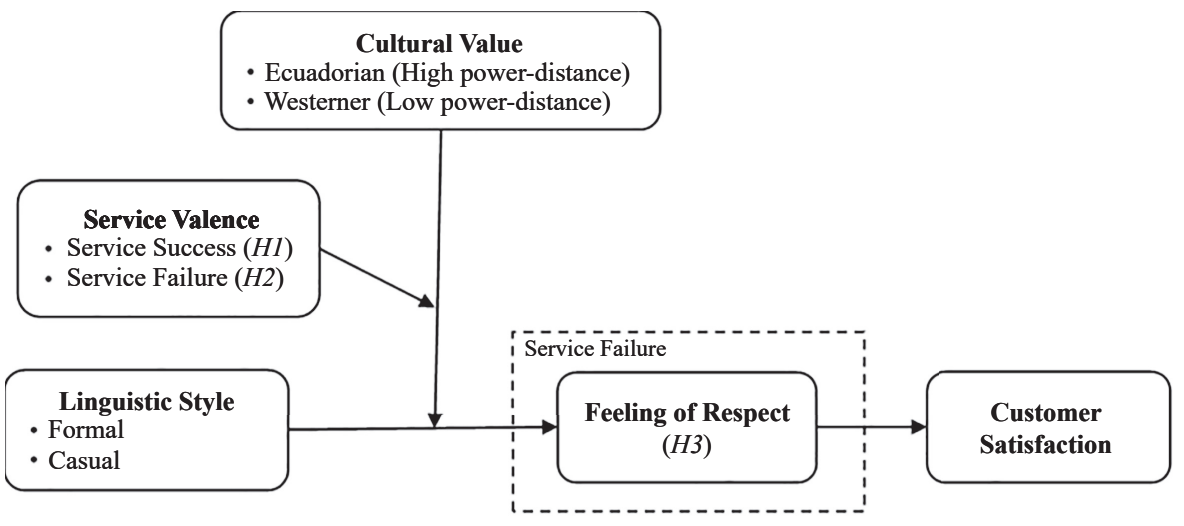

Figure 1 . Conceptual model of the current research 
next to each other for you and your friend as you desired." Then, participants read a welcome letter from the hotel general manager. Depending on the assigned scenario, participants were addressed either formally by a title (Mr./Ms.) and last name or casually by the first name only in the letter. Each participant read the hypothetical scenario and guest letter corresponding to his/her cultural background (Ecuadorian or Westerner) and gender (male or female). For example, an Ecuadorian female participant would read a hotel guest letter written in Spanish and addressed by a female Spanish title or name (e.g. Ms. Lopez or Maria). The scenarios and guest letters are provided in Appendix.

The scenarios and survey questions used in the current study were developed following the translation and back-translation method employed in previous cross-cultural studies (Brislin, 1970; Mattila, 1999). The scenarios and survey questions were first written in English, then translated into Spanish and then back-translated into English. The translation and back-translation processes were handled separately by two independent bilingual (i.e. Spanish and English) scholars (Brislin, 1970).

Participants. The final sample included a total of 142 adult participants who provided correct answers to the manipulation and attention check questions. Among the entire study sample, the gender split was $48.6 \%$ female vs $51.4 \%$ male; $96.5 \%$ were in the age range of 20-59 years, and $94.4 \%$ had at least some college education. In total, there were 80 Ecuadorian participants (female $=50 \%$, male $=50 \%$; all in the age range of $20-59$ years; $98.8 \%$ with at least some college education) and 62 Western participants (female $=46.8 \%$, male $=53.2 \%$; $92 \%$ in the age range of $20-59$ years; $88.7 \%$ with at least some college education). All of the Western participants came from low power-distance countries (www.geert-hofstede.com/countries): Australia, Canada, Ireland, Germany, New Zealand, Switzerland, the United Kingdom and the United States.

Measures. After reading the scenarios, the participants were instructed to complete a questionnaire based on the scenarios. The dependent variable of customer satisfaction was measured with a four-item, seven-point scale adapted from previous research (Westbrook and Oliver, 1981; Wu et al., 2015): "I am satisfied with the hotel," "I am happy with the hotel," "The hotel did a good job," and "Staying at this hotel was a good choice" (Scale reliability Cronbach's $\alpha=0.973$ ).

To confirm that high vs low power-distance participants were different in cultural orientation, participants' perceptions of power distance were measured with a two-item, seven-point scale adapted from Hofstede (1984): "When an appraisal made by the supervisor does not fit with subordinates' expectations, the subordinates should feel free to discuss it with the supervisor," and "In order to have efficient work relationships, it is often necessary to bypass hierarchical lines." The independent $t$-test results confirmed that the Ecuadorian participants scored significantly higher on the power distance scale than their Western counterparts $\left(M_{\text {Ecuadorian }}=4.075, M_{\text {Westerner }}=2.220, t=6.449, p\right.$-value $=0.000$; scale reliability Cronbach's $\alpha_{\mathrm{All}}=0.925$, Cronbach's $\alpha_{\text {Ecuadorian }}=0.915$, Cronbach's $\alpha_{\text {Westerner }}=0.816$ ).

Manipulation and realism checks. For the manipulation check, participants were asked to recall whether they eventually had two hotel rooms next to each other as they had requested in the scenario, and how they were addressed in the guest letter - either formally or casually. Participants who failed these manipulation checks were eliminated from the study. Scenario realism was checked by "How realistic was the scenario?" (1 - Extremely unrealistic to 7- Extremely realistic). Overall, the participants found the scenarios to be highly realistic $(M=5.30)$. There was no significant difference across the two cultural samples $\left(M_{\text {Ecuadorian }}=5.35, M_{\text {Westerner }}=5.24, t=0.530, p\right.$-value $\left.=0.597\right)$.

ANOVA results. To test $\mathrm{H} 1 \mathrm{a}$ and $\mathrm{H} 1 \mathrm{~b}$, we conducted a 2 (culture background: high vs low power distance) by 2 (linguistic style: formal vs casual) between-subjects ANOVA on 
customer satisfaction. Results of the ANOVA test revealed a significant interaction effect $\left(F_{(1,138)}=7.922, p\right.$-value $\left.=0.006\right)$. The ANOVA results are displayed in Table 1 .

To assess the hypotheses, simple main effect analyses were conducted. The simple main effect results are plotted in Figure 2. As visualized, Ecuadorians who rank high in power distance were significantly more satisfied when they were addressed formally by the title and last name (vs casually by first name) in the guest letter $\left(M_{\text {Formal }}=4.263\right.$ vs $M_{\text {Casual }}=3.163$, $F_{(1,138)}=11.199, p$-value $\left.=0.001\right)$. Thus, H1a was supported. On the other hand, this effect was attenuated for Westerners who ranked low in power distance orientation: regardless of how they were addressed in the guest letter (i.e. formally vs casually), they exhibited a similar level of satisfaction $\left(M_{\text {Formal }}=5.692\right.$ vs $M_{\text {Casual }}=5.992, F_{(1,138)}=0.647, p$-value $\left.=0.432\right)$. Therefore, H1b was supported as well.

Study 1 demonstrates that the cultural value of power distance plays an important role in shaping customers' service quality evaluations following a successful service transaction. Specifically, the effect of different power-distance orientation on customer satisfaction is reflected through customers' divergent expectations or preferences of service encounter styles. The results indicate that Ecuadorian customers (i.e. high power-distance) prefer more formal linguistic styles in hotel host-guest communications that emphasize the status difference between themselves and the service providers, while their Western counterparts (i.e. low power-distance) do not base their satisfaction ratings on this particular linguistic service clue.

\begin{tabular}{lcrrrr}
\hline Source & Type III SS & DF & MS & $F$ & $p$-value \\
\hline Corrected model & $184.707^{\mathrm{a}}$ & 3 & 61.569 & 28.492 & 0.000 \\
Culture & 158.294 & 1 & 158.294 & 73.253 & 0.000 \\
Linguistic style & 5.578 & 1 & 5.578 & 2.581 & 0.110 \\
Interaction effect & 17.118 & 1 & 17.118 & 7.922 & 0.006 \\
Error & 298.298 & 138 & 2.161 & & \\
Total & 3545.875 & 142 & & &
\end{tabular}

Note(s): ${ }^{\text {a }} R$ squared $=0.382$ (Adjusted $R$ squared $\left.=0.369\right)$

\section{Linguistic style and customer satisfaction}


Design and stimuli. Extending the investigation to the service failure condition, Study 2 employed the same 2 (culture background: high vs low power distance) by 2 (linguistic style: formal vs casual) between-subjects quasi-experimental design and procedures as Study 1. The study stimuli were similar to those used in Study 1, with the exception that the scenario indicated a service failure. All the participants in this study also read a hypothetical scenario: "For a recent trip, you had booked two connecting rooms for yourself and your friend; upon checking-in, the hotel was fully booked, and the front desk clerk could not provide the connecting rooms you had requested but allocated you and your friend to rooms on different floors." After that, the participants read an apology letter from the hotel general manager. Depending on the assigned scenario, participants were addressed either formally by a title (Mr./Ms.) and last name or casually by first name only in the letter. Each participant read the hypothetical scenario and guest letter corresponding to his/her cultural background (Ecuadorian or Westerner) and gender (male or female). The scenario and guest letters are provided in Appendix.

Participants. The final sample included a total of 147 adult participants who provided correct answers to the manipulation and attention check questions. Among the entire study sample, the gender split was $52.4 \%$ female vs $47.6 \%$ male; $73.5 \%$ were in the age range of 20 59 years, and $95.9 \%$ had at least some college education. In total, there were 80 Ecuadorian participants (female $=50 \%$, male $=50 \% ; 91.2 \%$ in the age range of $20-59$ years; $98.7 \%$ with at least some college education) and 67 Western participants (female $=55.2 \%$, male $=44.8 \%$; $92.5 \%$ in the age range of $20-59$ years; $92.5 \%$ with at least some college education). All the Western participants came from low power-distance countries, including Australia, Canada, Ireland, Switzerland, the United Kingdom and the United States.

Measures. After reading the scenarios, participants were directed to answer the survey questionnaire identical to that in Study 1. The dependent variable of customer satisfaction was measured by a four-item, seven-point scale adapted from previous research (Westbrook and Oliver, 1981; Wu et al., 2015), and the scale kept the same reliability level as in Study 1 with Cronbach's $\alpha=0.973$. The mediator of feeling of respect was measured by a single-item question: "After reading the letter, to what extent do you feel that you are respected by the hotel staff?” A two-item, seven-point scale adapted from Hofstede (1984) was used to measure the cultural differences in power-distance. The independent $t$-test results confirmed that Ecuadorian (vs Westerner) participants scored significantly higher on the power distance scale $\left(M_{\text {Ecuadorian }}=3.488, M_{\text {Westerner }}=2.632, t=2.717, p\right.$-value $=0.007$; scale reliability Cronbach's $\alpha_{\text {All }}=0.862$, Cronbach's $\alpha_{\text {Ecuadorian }}=0.813$, Cronbach's $\alpha_{\text {Westerner }}=0.911$ ).

Manipulation and realism checks. As in Study 1, participants who failed the manipulation checks were eliminated from the study. For the scenario realism check, the participants found the scenarios to be highly realistic $(M=6.08)$. There was no significant difference across the two cultural samples $\left(M_{\text {Ecuadorian }}=5.99, M_{\text {Westerner }}=6.19, t=-1.828, p\right.$-value $\left.=0.070\right)$.

ANOVA results. To test $\mathrm{H} 2$, we conducted a 2 (culture background: high vs low power distance) by 2 (linguistic style: formal vs casual) between-subjects ANOVA on customer satisfaction. Results of the ANOVA test revealed a significant main effect of the address form $\left(M_{\text {Casual }}=1.210, M_{\text {Formal }}=3.532, F_{(1,143)}=86.124, p\right.$-value $\left.=0.000\right)$. The ANOVA results are displayed in Table 2. Specifically, across the two cultural samples, participants showed the same pattern in their responses to different styles of address forms. As visualized in Figure 3, both Ecuadorians $\left(M_{\text {Casual }}=1.225\right.$ vs $M_{\text {Formal }}=3.819, F_{(1,143)}=59.781, p$-value $\left.=0.000\right)$ and Westerners $\left(M_{\text {Casual }}=1.190\right.$ vs $M_{\text {Formal }}=3.230, F_{(1,143)}=30.430, p$-value $\left.=0.000\right)$ exhibited a lower level of satisfaction when they were addressed casually rather than formally. Hence, $\mathrm{H} 2$ was supported.

Mediation results. To test the proposed psychological mechanism via feeling of being respected (to test H3), a mediation test was performed following the PROCESS procedure 
(Model 4) and its recommended bootstrap technique. PROCESS model 4 allows researchers to test the mediation effect and the underlying psychological mechanism in a more rigorous way (Hayes, 2013). The bootstrap result shows that, in a service failure scenario, the impact of different linguistic styles of address forms (i.e. formal vs casual) on customer satisfaction was driven by customers' feeling of being respected $(\beta=-0.692,95 \%$ bootstrap interval: -1.054 , $-0.374)$; therefore, $\mathrm{H} 3$ was supported.

Study 2 reveals that following a service failure, customers' satisfaction ratings will be lower when they see the usage of casual (vs formal) linguistic clues in the service providers' guest communications, regardless of their power-distance orientations. The follow-up mediation test further confirms that customers' feeling of being respected is the psychological mechanism explaining the negative effect of the casual address form on customer satisfaction across the two cultural groups. This finding corroborates previous research showing that employee courtesy as reflected in the usage of a formal linguistic style can enhance customers' self-image and increase their feelings of self-worth, which is particularly important to customers in a service failure scenario (Du et al., 2010; Gotlieb et al., 2004; Patterson et al., 2006).

\section{Discussion}

\section{Conclusions}

Drawing on the dual process theory (i.e. System 1 vs System 2 thinking) and the cultural dimension of power distance, this research investigates the impact of a specific hospitality

\begin{tabular}{lrrrrr}
\hline Source & Type III SS & DF & \multicolumn{1}{c}{ MS } & \multicolumn{1}{c}{$F$} & $p$-value \\
\hline Corrected model & $204.155^{\mathrm{a}}$ & 3 & 68.052 & 30.236 & 0.000 \\
Culture & 3.512 & 1 & 3.512 & 1.561 & 0.214 \\
Linguistic style & 193.841 & 1 & 193.841 & 86.124 & 0.000 \\
Interaction effect & 2.761 & 1 & 2.761 & 1.227 & 0.270 \\
Error & 321.853 & 143 & 2.251 & & \\
Total & 1402.750 & 147 & & &
\end{tabular}

Note(s): ${ }^{a} R$ squared $=0.388$ (Adjusted $R$ squared $=0.375$ )

\section{Linguistic style and customer satisfaction}

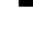

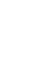


service clue — the linguistic style of guest letter address forms (i.e. formal vs casual)—on customer satisfaction across different service situations (i.e. service success vs service failure). The results confirm a culture-bound effect of linguistic style following a successful service transaction, where the usage of formal address form leads to higher level of satisfaction for Ecuadorian customers (i.e. high power-distance cultural oriented), while the satisfaction level of Westerner customers (i.e. low power-distance cultural oriented) is not influenced. On the other hand, following a service failure, the cultural differences between customers are attenuated, as the expectation of high-level employee courtesy and desired feeling of respect is shared by customers from both cultural groups. Customers appreciate a formally (vs casually) addressed guest letter with a higher level of satisfaction regardless of their different cultural orientations.

\section{Theoretical implications}

This research presents new insight into the largely overlooked topic of linguistic clues in hospitality services. The subjects of hospitality language, linguistic expression and communication style, along with the related topic of employee courtesy, have received limited attention from hospitality scholars (Blue and Harun, 2003; Kim and Baker, 2019; Mattila, 1999), regardless of their relevance and importance in the service domain. With little empirical evidence, previous research presents conflicting perspectives regarding the effect of employee courtesy on customers' attitudes toward a service firm: some believe that courtesy is highly valued by customers and leads to positive results for an organization, while others argue that such implicit service clues have little effect on customers' service evaluation (Gotlieb et al., 2004). The current study addresses this controversy by operationalizing employee courtesy in terms of formal language use and by empirically identifying the conditions in which such a service clue is likely to have a stronger impact on customer satisfaction. In particular, we adopted two sets of variables-cultural background and service valence - to characterize such conditions, which, to the authors' best knowledge, has never been studied in previous research.

Furthermore, the current study extends Solomon et al's (1985) role theory by demonstrating that the concept of service encounters as role performances still holds in the context of written materials relevant to the service delivery, such as hotel guest letters. On-site communications between hospitality service providers and customers have predominantly been investigated in the format of face-to-face encounters or spoken language (Blue and Harun, 2003; Scerri, 2014). In Solomon et al's (1985) seminal work, service encounters were limited to only in-person interactions, and the researchers called for future studies to examine whether role expectations and behaviors operate similarly in other service situations. The findings of the current research confirm that customers expect the appropriate roles to be played by service providers even when the communication is delivered in writing. This study further reflects the intricacy of service encounters and the importance of understanding customer satisfaction as a function of role expectations and perceived performances (Solomon et al., 1985).

The current research also sheds light on the application of dual process theory in an effort to understand customers' responses to linguistic service clues in a hotel context. The linguistic style of hospitality service communications is usually considered a surface message feature or a peripheral cue, which is typically processed by customers in an effortless reflexive mode (Liu and Shrum, 2009; Meyers-Levy and Maheswaran, 2004). However, results from this research show that a peripheral message cue can also be processed in a more deliberative mode, depending on the specific situation (Liu and Shrum, 2009; Samson and Voyer, 2012). In this regard, the present study enriches the dual process framework in the context of service encounters by highlighting service valence as a critical condition under which different information processing modes can be evoked. 
Relatedly, this research provides empirical evidence showing that the moderating effects of cultural values can become either salient or attenuated in different service contexts. Utilizing an experimental design, we demonstrate that following a successful service transaction, as customers tend to adopt the automatic and uncontrolled System 1 thinking to process the linguistic service clues, factors internal to the customer, such as their default cultural values, become the most salient determinant of customer responses (Berry et al., 2006; Solomon et al., 1985). Alternatively, a service failure situation can trigger customers' adoption of the deliberate and elaborative System 2 thinking (Schwarz, 2000; Solomon et al., 1985), through which they focus their cognitive capacity on the potential information incongruence arising from the discrepancy between the perceived and expected levels of employee courtesy. As a result, the impact of cultural factors on customer satisfaction is diminished; instead, customers consciously interpret the information to evaluate whether they have been treated by the service providers with sufficient respect.

\section{Managerial implications}

The findings of this study present important implications for service providers in general and for hotel managers and employees in particular. Service encounters are essentially social exchange processes, which are culturally contingent (Patterson et al., 2006). As cross-cultural interactions between service providers and customers become increasingly prevalent in today's service landscape, it is vital to increase service employees' cultural awareness and enhance their socio-linguistic knowledge and pragmatic skills to achieve effective host-guest communications to ensure customer satisfaction (Blue and Harun, 2003; Sirikhan and Prapphal, 2011). Especially in a hotel context, service employees are likely to focus on the common patterns and regularities of hospitality language, yet might overlook the contextspecific effect of such linguistic expressions (Blue and Harun, 2003). This study reveals that even a seemingly trivial linguistic service clue (i.e. the usage of formal address forms in guest letters) can make a difference, leading to significantly higher levels of satisfaction for certain customer groups (i.e. from high power-distance cultures) or in a particular service scenario (i.e. following a service failure). Thus, hotel management is well advised to provide continuous training to help their employees develop cultural consciousness and socio-linguistic sensitivity.

There is a growing trend in the hospitality industry to move away from the traditional service styles of "grand hotel formality" (King, 1995) and adopt more modern, informal approaches that provide customers with feelings of ease and authenticity (Minett, 2019; Osman et al., 2009; Simonsen et al., 2020). Such a change is reflected in the company culture, marketing communications and operational practices across different tiers of brands, from midscale to upscale and luxury hotels around the world (Minett, 2019; Shankman, 2018). The strategic employment of informal styles can convey perceptions of closeness, reduce social distance and foster customer-brand relationships (Gretry et al., 2017). Especially for high-end hotel properties, these more casual and simplified service philosophies can represent more personable and genuine brand images and thus differentiate them from the competitors (Minett, 2019; Osman et al., 2009; Shankman, 2018). However, the current research findings suggest that hospitality practitioners should adopt such informal service styles with caution.

Specifically, when communicating with customers in a service failure situation, it is not advisable to use informal linguistic styles. Although previous research indicates that such a casual, conversational tone can humanize the corporate voice and mitigate negative evaluations from customers (van Noort and Willemsen, 2012), the current study demonstrates otherwise: after a service failure, customers increasingly desire highlighted formality that reflects high-level respect from the service providers regardless of customers' cultural backgrounds. In the context of neutral or positive service experiences, customers' reactions toward the adoption of informal styles depend on their subjective preferences,

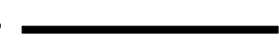


which are largely shaped by sociodemographic factors such as customers' cultural values. As such, hotel managers should maintain updated knowledge of their target customer segments and a heightened awareness of variability among customers.

As the hospitality industry slowly recovers from the pandemic and hotels take measures to minimize human-to-human contact in order to ensure employees' and customers' health and safety (Gursoy and Chi, 2020), hotel guest letters become one of the few platforms where the "hosts" can deliver their personalized greetings and communications to the customers in a contactless way. Therefore, a great deal of attention needs to be paid to the details of these communication opportunities, such as customizing the content and style of the letter according to the specific context, the guest's cultural orientation or other relevant customer characteristics. Efforts to convey high-level consideration and respect will highlight an invaluable human touch as a core element of hospitality in the "new normal" service practices that are marked by physical distancing and reduced human contact and will result in enhanced customer satisfaction.

This research also provides managerial guidelines for hospitality practitioners in Ecuador, an environment that has been understudied in the extant cross-cultural hospitality research. Known for its unique ecology and biodiversity and its focus on ecotourism (Burbano and Meredith, 2020), Ecuador is likely to receive an influx of international visitors as international tourism further develops. Leveraging the results of this study, Ecuadorian hotel practitioners should pay more attention to the different cultural orientations of both domestic and foreign tourists and be aware of their divergent expectations and preferences of service styles in order to provide satisfactory experiences to diverse customer groups.

\section{Limitations and future research}

The present research has some limitations that warrant attention. First, we used hypothetical service scenarios as stimuli to collect responses from the study samples. Field studies are needed in the future to further understand the effect of linguistic service clues on hotel customer satisfaction across different cultural groups and service situations. Second, we limited the investigation to a specific service clue - the linguistic style of address forms in hotel guest letters. Future studies may examine similar hospitality linguistic clues present in other channels (e.g. verbal conversations, online platforms) to improve the generalizability of the current findings. Third, the current study only examined one dependent variable of customer satisfaction. Future research may extend from the current attitudinal response (i.e. customer satisfaction) to the downstream behavioral responses such as customers' word-of-mouth and revisit intentions for further investigation. Finally, this research focused on power-distance orientation as the cultural value that may influence customers' reactions to different linguistic styles in service encounters. Other cultural dimensions, such as high vs low context and tightness vs looseness (Mattila, 2019), may also drive customer attitudes and behaviors in different directions in response to various linguistic expressions and communication styles in hospitality services and could be investigated in future research.

\section{References}

Barcelos, R.H., Dantas, D.C. and Sénécal, S. (2018), "Watch your tone: how a brand's tone of voice on social media influences consumer responses", Journal of Interactive Marketing, Vol. 41, pp. 60-80.

Berry, L.L., Wall, E.A. and Carbone, L.P. (2006), "Service clues and customer assessment of the service experience: lessons from marketing", Academy of Management Perspectives, Vol. 20 No. 2, pp. 43-57.

Blue, G.M. and Harun, M. (2003), "Hospitality language as a professional skill", English for Specific Purposes, Vol. 22 No. 1, pp. 73-91. 
Brislin, R.W. (1970), "Back-translation for cross-cultural research", Journal of Cross-Cultural Psychology, Vol. 1 No. 3, pp. 185-216.

Burbano, D.V. and Meredith, T.C. (2020), "Effects of tourism growth in a UNESCO world heritage site: resource-based livelihood diversification in the galapagos islands, Ecuador", Journal of Sustainable Tourism. doi: 10.1080/09669582.2020.1832101.

Chen, M.-H., Chen, B.H. and Chi, C.G. (2019), "Socially responsible investment by generation Z: a crosscultural study of Taiwanese and American investors", Journal of Hospitality Marketing and Management, Vol. 28 No. 3, pp. 334-350.

Chon, K., Park, E. and Zoltan, J. (2020), "The Asian paradigm in hospitality and tourism”, Journal of Hospitality and Tourism Research, Vol. 44 No. 8, pp. 1183-1202.

de Mooij, M. (1998), Global Marketing and Advertising: Understanding Cultural Paradoxes, Sage Publications, Thousand Oaks, CA.

Daniels, M.A. and Greguras, G.J. (2014), "Exploring the nature of power distance: implications for micro-and macro-level theories, processes, and outcomes", Journal of Management, Vol. 40 No. 5, pp. 1202-1229.

Dash, S., Bruning, E. and Acharya, M. (2009), "The effect of power distance and individualism on service quality expectations in banking”, International Journal of Bank Marketing, Vol. 27 No. 5, pp. 336-358.

Donthu, N. and Yoo, B. (1998), "Cultural influences on service quality expectations”, Journal of Service Research, Vol. 1 No. 2, pp. 178-186.

Du, J., Fan, X. and Feng, T. (2010), "An experimental investigation of the role of face in service failure and recovery encounters", Journal of Consumer Marketing, Vol. 27 No. 7, pp. 584-593.

Fan, A., Van Hoof, H.B., Loyola, S.P., Lituma, S.C. and Granda, M.J. (2016), "The impact of other customers and gender on consumer complaint behaviour in the Ecuadorian restaurant setting", European Journal of Tourism, Hospitality and Recreation, Vol. 7 No. 1, pp. 21-29.

Glikson, E., Rees, L., Wirtz, J., Kopelman, S. and Rafaeli, A. (2019), "When and why a squeakier wheel gets more grease: the influence of cultural values and anger intensity on customer compensation", Journal of Service Research, Vol. 22 No. 3, pp. 223-240.

Gotlieb, J., Levy, M., Grewal, D. and Lindsey-Mullikin, J. (2004), "An examination of moderators of the effects of customers' evaluation of employee courtesy on attitude toward the service firm", Journal of Applied Social Psychology, Vol. 34 No. 4, pp. 825-847.

Gretry, A., Horváth, C., Belei, N. and van Riel, A.C. (2017), “Don’t pretend to be my friend!' when an informal brand communication style backfires on social media", Journal of Business Research, Vol. 74, pp. 77-89.

Gursoy, D. and Chi, C.G. (2020), "Effects of COVID-19 pandemic on hospitality industry: review of the current situations and a research agenda", Journal of Hospitality Marketing and Management, Vol. 29 No. 5, pp. 527-529.

Hayes, A.F. (2013), Introduction to Mediation, Moderation, and Conditional Process Analysis: A Regression-Based Approach, Guilford Press, New York, NY.

Hofstede, G. (1984), Culture's Consequences: International Differences in Work Related Values, Sage Publications, Newbury Park, CA.

Hofstede, G. (2001), Culture's Consequences: Comparing Values, Behaviors, Institutions and Organizations across Nations, Sage Publications, Thousand Oaks, CA.

Hofstede, G. (2011), "Dimensionalizing cultures: the Hofstede model in context", Online Readings in Psychology and Culture, Vol. 2 No. 1, pp. 2307-0919.

Hofstede Insights (n.d.), "What about Ecuador?", available at: https://www.hofstede-insights.com/ country/ecuador/ (accessed 9 January 2021).

Javidan, M. and House, R.J. (2001), "Cultural acumen for the global manager: lessons from Project GLOBE”, Organizational Dynamics, Vol. 29 No. 4, pp. 289-305.
Linguistic style and customer satisfaction 
Kahneman, D. (2011), Thinking, Fast and Slow, Farrar, Straus and Giroux, New York, NY.

Kim, C.S. and Aggarwal, P. (2016), "The customer is king: culture-based unintended consequences of modern marketing", Journal of Consumer Marketing, Vol. 33 No. 3, pp. 193-201.

Kim, K. and Baker, M.A. (2019), "How the employee looks and looks at you: building customeremployee rapport", Journal of Hospitality and Tourism Research, Vol. 43 No. 1, pp. 20-40.

King, C.A. (1995), "What is hospitality?", International Journal of Hospitality Management, Vol. 14 Nos 3/4, pp. 219-234.

Koc, E. (2019), "Service failures and recovery in hospitality and tourism: a review of literature and recommendations for future research", Journal of Hospitality Marketing and Management, Vol. 28 No. 5, pp. 513-537.

Koh, Y., Lee, M., Kim, J. and Yang, Y.Y. (2020), "Successful restaurant crowdfunding: the role of linguistic style", International Journal of Contemporary Hospitality Management, Vol. 32 No. 10, pp. 3051-3066.

Ladhari, R., Pons, F., Bressolles, G. and Zins, M. (2011), "Culture and personal values: how they influence perceived service quality”, Journal of Business Research, Vol. 64 No. 9, pp. 951-957.

Lam, R., Cheung, C. and Lugosi, P. (2020), "The impacts of cultural and emotional intelligence on hotel guest satisfaction: Asian and non-Asian perceptions of staff capabilities", Journal of China Tourism Research. doi: 10.1080/19388160.2020.1771500.

Lee, H.E. (2015), "Does a server's attentiveness matter? Understanding intercultural service encounters in restaurants", International Journal of Hospitality Management, Vol. 50, pp. 134-144.

Li, M. (2014), "Cross-cultural tourist research: a meta-analysis", Journal of Hospitality and Tourism Research, Vol. 38 No. 1, pp. 40-77.

Liu, Y. and Shrum, L.J. (2009), “A dual-process model of interactivity effects”, Journal of Advertising, Vol. 38 No. 2, pp. 53-68.

Manoharan, A., Gross, M.J. and Sardeshmukh, S.R. (2021), "Antecedents and outcomes of a culturally diverse workforce in hotels", Journal of Hospitality and Tourism Research. doi: 10.1177/ 1096348020986906.

Mattila, A.S. (1999), "The role of culture in the service evaluation process", Journal of Service Research, Vol. 1 No. 3, pp. 250-261.

Mattila, A.S. (2000), "The impact of culture and gender on customer evaluations of service encounters", Journal of Hospitality and Tourism Research, Vol. 24 No. 2, pp. 263-273.

Mattila, A.S. (2019), "A commentary on cross-cultural research in hospitality and tourism inquiry", International Journal of Hospitality Management, Vol. 76, pp. 10-12.

Meyers-Levy, J. and Maheswaran, D. (2004), "Exploring message framing outcomes when systematic, heuristic, or both types of processing occur", Journal of Consumer Psychology, Vol. 14 Nos 1-2, pp. 159-167.

Minett, D. (2019), "Should your hotel embrace a more informal service model?", available at: https:// www.4hoteliers.com/features/article/12133 (accessed 16 May 2021).

Moors, A. (2016), "Automaticity: componential, causal, and mechanistic explanations”, Annual Review of Psychology, Vol. 67, pp. 263-287.

Osman, H., Hemmington, N. and Bowie, D. (2009), "A transactional approach to customer loyalty in the hotel industry", International Journal of Contemporary Hospitality Management, Vol. 21 No. 3, pp. 239-250.

Patterson, P.G., Cowley, E. and Prasongsukarn, K. (2006), "Service failure recovery: the moderating impact of individual-level cultural value orientation on perceptions of justice", International Journal of Research in Marketing, Vol. 23 No. 3, pp. 263-277. 
Pogacar, R., Shrum, L.J. and Lowrey, T.M. (2018), "The effects of linguistic devices on consumer information processing and persuasion: a language complexity x processing mode framework", Journal of Consumer Psychology, Vol. 28 No. 4, pp. 689-711.

Ruiz-Ballesteros, E. (2011), "Social-ecological resilience and community-based tourism: an approach from Agua Blanca, Ecuador”, Tourism Management, Vol. 32 No. 3, pp. 655-666.

Ruiz-Equihua, D., Romero, J. and Casaló, L.V. (2020), "Better the devil you know? The moderating role of brand familiarity and indulgence vs. restraint cultural dimension on eWOM influence in the hospitality industry", Journal of Hospitality Marketing and Management, Vol. 29 No. 3, pp. 310-328.

Samson, A. and Voyer, B.G. (2012), "Two minds, three ways: dual system and dual process models in consumer psychology", AMS Review, Vol. 2, pp. 48-71.

Scerri, M.A. (2014), "The language of service in Australia's luxury hotels: a grounded theory approach", available at: http://citeseerx.ist.psu.edu/viewdoc/download?doi=10.1.1.874. $5488 \&$ rep $=$ rep1\&type $=$ pdf (accessed 16 May 2021).

Schuckert, M., Liu, X. and Law, R. (2015), "A segmentation of online reviews by language groups: how English and non-English speakers rate hotels differently", International Journal of Hospitality Management, Vol. 48, pp. 143-149.

Schwarz, N. (2000), "Emotion, cognition, and decision making”, Cognition and Emotion, Vol. 14 No. 4, pp. $433-440$.

Shankman, S. (2018), "Being informal is the future of luxury guest relations", available at: https://skift. com/2018/03/27/being-informal-is-the-future-of-luxury-guest-relations/ (accessed 16 May 2021).

Simonsen, D., Vejlgaard, H. and Nissen, R. (2020), "Informal \& relaxed: exercising the role of host in the hospitality industry in Denmark", paper presented at EuroCHRIE 2020, 10 June-10 August, Aalborg, Denmark, available at: https://www.ucviden.dk/da/publications/informal-amp-relaxedexercising-the-role-of-host-in-the-hospitali (accessed 16 May 2021).

Sirikhan, S. and Prapphal, K. (2011), "Assessing pragmatic ability of Thai hotel management and tourism students in the context of hotel front office", Asian EFL Journal Professional Teaching Articles, Vol. 53, pp. 72-94.

Solomon, M.R., Surprenant, C., Czepiel, J.A. and Gutman, E.G. (1985), "A role theory perspective on dyadic interactions: the service encounter", Journal of Marketing, Vol. 49 No. 1, pp. 99-111.

$\mathrm{Su}$, N., Min, H., Chen, M.H. and Swanger, N. (2018), "Cultural characteristics and tourist shopping spending", Journal of Hospitality and Tourism Research, Vol. 42 No. 8, pp. 1210-1231.

Surachartkumtonkun, J., Patterson, P.G. and McColl-Kennedy, J.R. (2013), "Customer rage back-story: linking needs-based cognitive appraisal to service failure type”, Journal of Retailing, Vol. 89 No. 1, pp. $72-87$.

van Noort, G. and Willemsen, L.M. (2012), "Online damage control: the effects of proactive versus reactive webcare interventions in consumer-generated and brand-generated platforms", Journal of Interactive Marketing, Vol. 26 No. 3, pp. 131-140.

Wang, X., Tang, L.R. and Kim, E. (2019), "More than words: do emotional content and linguistic style matching matter on restaurant review helpfulness?", International Journal of Hospitality Management, Vol. 77, pp. 438-447.

Westbrook, R.A. and Oliver, R.L. (1981), "Developing better measures of consumer satisfaction: some preliminary results", ACR North American Advances, Vol. 8, pp. 94-99.

Winsted, K.F. (1997), "The service experience in two cultures: a behavioral perspective", Journal of Retailing, Vol. 73 No. 3, pp. 337-360.

Wood, L.A. and Kroger, R.O. (1991), "Politeness and forms of address", Journal of Language and Social Psychology, Vol. 10 No. 3, pp. 145-168.

Wu, L., Fan, A. and Mattila, A.S. (2015), "Wearable technology in service delivery processes: the gender-moderated technology objectification effect”, International Journal of Hospitality Management, Vol. 51, pp. 1-7. 

projectabroad.eu/power-distance-what-does-it-mean-to-be-a-good-boss/ (accessed 1 March 2021).

\section{Appendix}

Names used in the scenarios corresponding to participants' cultural background and gender:

(1) José Lopez - for Ecuadorian male participants.

(2) María Lopez - for Ecuadorian female participants.

(3) Jack Jones - for Westerner male participants.

(4) Mary Jones - for Westerner female participants.

\section{Study 1 - Service success}

For a recent trip, you (José Lopez/Jack Jones/María Lopez/Mary Jones) had booked two rooms one for yourself, the other for a friend. Upon checking-in, the hotel was fully booked, but the front desk clerk took great effort to find two rooms next to each other for you and your friend. Later that night, after you had gone out for a meal, you came back and found a welcome letter from the hotel general manager in your room. The letter said:

Dear Mr. Lopez/Mr. Jones/Ms. Lopez/Ms. Jones (formal form scenarios),

Dear José/Jack/María/Mary (casual form scenarios),

Thank you for choosing our hotel!' I am glad that we could assist you in finding the rooms that met your needs. Hope you have a pleasant stay with us.

Best regards,

Rafael Varga

Hotel General Manager

\section{Study 2 - Service failure}

For a recent trip, you (José Lopez/Jack Jones/María Lopez/Mary Jones) had booked two connecting rooms - one for yourself, the other for a friend. Upon checking-in, the hotel was fully booked and the front desk clerk told you that there were no connecting rooms available, yet there were two separate rooms on different floors for you and your friend. Later that night, after you had gone out for a meal, you came back and found an apology letter from the hotel general manager in your room. The letter said:

Dear Mr. Lopez/Mr. Jones/Ms. Lopez/Ms. Jones (formal form scenarios),

Dear José/Jack/María/Mary (casual form scenarios),

Thank you for choosing our hotel!' I am sorry that we could not assist you in finding the rooms that met your needs. My sincere apologies for this, I hope you have a pleasant stay with us.

Best regards,

Rafael Varga

Hotel General Manager

\section{Corresponding author}

Alei Fan can be contacted at: fan182@purdue.edu

For instructions on how to order reprints of this article, please visit our website:

www.emeraldgrouppublishing.com/licensing/reprints.htm

Or contact us for further details: permissions@emeraldinsight.com 